\title{
PENGARUH METODE DEMONSTRASI TERHADAP HASIL BELAJAR FISIKA KELAS X MA ALMUHAJIRIN TUGUMULYO
}

\author{
Ovilia Putri Utami Gumay ${ }^{1}$, Venes Bertiana ${ }^{2}$ \\ Program Studi Pendidikan Fisika, STKIP PGRI Lubuklinggau ${ }^{1,2}$ \\ oviliaputri@ stkippgri-lubuklinggau.ac.id ${ }^{1}$ \\ Submit, 02-06-2018 Accepted, 26-06-2018 Publish, 26-06-2018
}

\begin{abstract}
: the purpose of this research is to know the student learning activity on the implementation of Demonstration model. The type of this research is quantitative with experimental research method with pre-test description post-test control group design or experimental control group design. The population in this study were all students of class X MA Al-Muhajirin Tugumulyo, two classes were taken randomly that is class X1 as experiment class and class X2 as control class. Technique of collecting data using test technique, test score data of student analyzed by using t-test. Based on the analysis of post-test data of experimental class and control class with significant level $\alpha=0,05$ obtained tcount: 6.87 and ttable: 2.02 because $t$ count $>$ t table then Ha accepted which means the average of experiment class grade is not same with class control. So it can be concluded that there is a significant influence Demonstration Method on Physics Learning Results class X Ma Al-Muhajirin Tugumulyo 2016/2017.
\end{abstract}

Keywords: Demonstration Learning Model, Learning Outcomes.

Abstrak: tujuan penelitian adalah untuk mengetahui aktivitas belajar siswa pada pelaksanaan model Demonstrasi. Jenis penelitian ini adalah kuantitatif dengan metode penelitian eksperimen dengan desain pre-test post-test control group design atau desain kelompok kontrol eksperimen. Populasi pada penelitian ini adalah seluruh siswa kelas X MA Al-Muhajirin Tugumulyo, dua kelas diambil secara acak yaitu kelas $X_{1}$ sebagai kelas eksperimen dan kelas $X_{2}$ sebagai kelas kontrol. Teknik pengumpulan data menggunakan teknik tes, data skor tes siswa dianalisis dengan menggunakan uji-t. Berdasarkan hasil analisis data posttest kelas eksperimen dan kelas kontrol dengan taraf signifikan $\alpha=0,05$ didapat $t_{\text {hitung }}: 6.87$ dan $t_{\text {tabel }}$ : 2,02 karena $t_{\text {hitung }}>t_{\text {tabel }}$ maka Ha diterima yang berarti rata-rata nilai kelas eksperimen tidak sama dengan kelas kontrol. Jadi dapat disimpulkan bahwa ada pengaruh yang signifikan Metode Demonstrasi terhadap Hasil Belajar Fisika kelas X Ma Al-Muhajirin Tugumulyo tahun 2016/2017.

Kata Kunci : Model pembelajaran Demonstrasi, Hasil Belajar.

PENDAHULUAN

Berdasarkan wawancara penulis dengan guru di MA Al-Muhajirin mengatakan bahwa hasil belajar siswa pada mata pelajaran fisika masih cukup rendah di bawah kriteria ketuntasan minimum (KKM) yang ditetapkan yaitu 74, dengan ketuntasan belajar klasikal sebesar $85 \%$. Jumlah siswa kelas $\mathrm{X}$ sebanyak 315 orang. Berdasarkan Ulangan Tengah Semester genap tahun pelajaran 2015/2016 diperoleh data siswa yang mencapai ketuntasan belajar sebesar $66,7 \%$ atau sebanyak 80 orang siswa yang tuntas dan yang tidak tuntas sebesar $33,3 \%$ atau sebanyak 40 orang.
Hasil ini menunjukkan ketuntasan belajar siswa belum memuaskan secara klasikal atau keseluruhan Selain itu, pencapaian hasil belajar siswa yang rendah juga disebabkan oleh: 1) Siswa kurang menyukai pelajaran fisika, 2) Siswa kurang memahami konsep-konsep sehingga tidak mampu menghubungkan materi pelajaran yang baru dengan materi sebelumnya, dan 3) Siswa masih belajar dengan cara hapalan untuk memahami konsep-konsep dalam pelajaran fisika.

Dengan menerapkan metode pembelajaran diharapkan dapat meningkatkan hasil belajar siswa. Metode pembelajaran yang dimaksudkan untuk mengupayakan agar pembelajaran yang 
berpusat pada guru berubah menjadi terpusat pada siswa. Metode pembelajaran tersebut adalah metode pembelajaran demonstrasi.

Berdasarkan wawancara penulis dengan guru di MA Al-Muhajirin mengatakan bahwa hasil belajar siswa pada mata pelajaran fisika masih cukup rendah di bawah kriteria ketuntasan minimum (KKM) yang ditetapkan yaitu 74 , dengan ketuntasan belajar klasikal sebesar 85\%. Jumlah siswa kelas $\mathrm{X}$ sebanyak 315 orang. Berdasarkan Ulangan Tengah Semester genap tahun pelajaran 2015/2016 diperoleh data siswa yang mencapai ketuntasan belajar sebesar $66,7 \%$ atau sebanyak 80 orang siswa yang tuntas dan yang tidak tuntas sebesar 33,3\% atau sebanyak 40 orang.

Hasil ini menunjukkan ketuntasan belajar siswa belum memuaskan secara klasikal atau keseluruhan Selain itu, pencapaian hasil belajar siswa yang rendah juga disebabkan oleh: 1) Siswa kurang menyukai pelajaran fisika, 2) Siswa kurang memahami konsep-konsep sehingga tidak mampu menghubungkan materi pelajaran yang baru dengan materi sebelumnya, dan 3) Siswa masih belajar dengan cara hapalan untuk memahami konsep-konsep dalam pelajaran fisika.

Dengan menerapkan metode pembelajaran diharapkan dapat meningkatkan hasil belajar siswa. Metode pembelajaran yang dimaksudkan untuk mengupayakan agar pembelajaran yang berpusat pada guru berubah menjadi terpusat pada siswa.

Metode pembelajaran tersebut adalah metode pembelajaran demonstrasi. Berdasarkan uraian di atas maka peneliti tertarik untuk melakukan penelitian dengan judul "Pengaruh Metode Demonstrasi terhadap hasil belajar fisika siswa kelas $\mathrm{X}$ MA AL Muhajirin Tugumulyo tahun ajaran 2016/2017". Tujuan penelitian ini adalah untuk mengetahui ketuntasan hasil belajar Fisika siswa kelas X MA Al Muhajirin tahun ajaran 2016/2017 setelah diterapkan Metode Deminstrasi.

\section{LANDASAN TEORI}

Menurut Djamarah (1997) metode demonstrasi adalah metode cara penyajian bahan pelajaran dengan meragakan atau mempertunjukkan kepada siswa suatu proses, situasi, atau benda tertentu yang sedang dipelajari, baik sebenarnya atau tiruan, yang sering disertai dengan penjelasan lisan. Menurut Sagala (dalam Majid, 2013) metode demonstrasi adalah petunjuk tentang proses terjadinya suatu peristiwa atau benda sampai pada penampilan tingkah laku yang dicontohkan agar dapat diketahui dan dipahami oleh peserta didik secara nyata. Menurut Sudjana (2004) metode demonstrasi adalah metode mengajar yang sangat efektif, sebab membantu para siswa untuk mencari jawaban dengan usaha sendiri berdasarkan fakta (data) yang benar.

\section{METODE PENELITIAN}

Adapun desain penelitian yang digunakan berbentuk pretest-posttest control group desain yang melibatkan dua kelompok seperti pada tabel 1 berikut

Tabel 1 Desain Pretes-posttest Control Group Desain.

\begin{tabular}{llll}
\hline Group & Pre-test & Treatmen & Post-test \\
\hline Eks & $\mathrm{Y}_{1}$ & $\mathrm{X}$ & $\mathrm{Y}_{2}$ \\
Kontrol & $\mathrm{Y}_{1}$ & - & $\mathrm{Y}_{2}$ \\
\hline
\end{tabular}

Keterangan :

$\mathrm{Y}_{1}$ : tes awal (pre-test)

$\mathrm{Y}_{2}$ : tes akhir (post-test)

$\mathrm{X}$ : perlakukan metode demonstrasi

- :perlakukaan pembelajaran dengan metode Ceramah dan Tanya jawab.

Populasi penelitian ini adalah seluruh siswa kelas $\mathrm{X}$ yang berjumlah 315 siswa untuk lebih jelasnya mengenai jumlah siswa kelas $\mathrm{X}$ MA Al-Muhajirin 2016/2017. Dapat dilihat pada tabel 2. 
Tabel 2 Populasi Penelitian

\begin{tabular}{cllll}
\hline No & Kelas & $\begin{array}{l}\text { Laki- } \\
\text { laki }\end{array}$ & $\begin{array}{l}\text { Perempu } \\
\text { an }\end{array}$ & $\begin{array}{l}\text { Jumlah } \\
\text { siswa }\end{array}$ \\
\hline $\mathbf{1}$ & $\mathrm{X}_{1}$ & 12 & 15 & 27 \\
$\mathbf{2}$ & $\mathrm{X}_{2}$ & 16 & 13 & 29 \\
$\mathbf{3}$ & $\mathrm{X}_{3}$ & 17 & 19 & 36 \\
$\mathbf{4}$ & $\mathrm{X}_{4}$ & 18 & 17 & 35 \\
$\mathbf{5}$ & $\mathrm{X}_{5}$ & 16 & 15 & 31 \\
$\mathbf{6}$ & $\mathrm{X}_{6}$ & 14 & 15 & 29 \\
$\mathbf{7}$ & $\mathrm{X}_{7}$ & 14 & 16 & 30 \\
$\mathbf{8}$ & $\mathrm{X}_{8}$ & 12 & 17 & 29 \\
$\mathbf{9}$ & $\mathrm{X}_{9}$ & 12 & 20 & 32 \\
$\mathbf{1 0}$ & $\mathrm{X}_{10}$ & 11 & 16 & 27 \\
\hline & & Jumlah & & 315 \\
\hline
\end{tabular}

Pengambilan sampel dari populasi yang ada dalam penelitian ini menggunakan teknik Simple Random Sampling, artinya pengambilan sampel dilakukan secara acak (dengan cara diundi) karena semua kelas yang akan dijadikan sampel memiliki kesempatan yang sama. Sistem pengambilan dilakukan dengan cara arisan, masing-masing nama kelas $\mathrm{X}$ ditulis dalam secarik kertas kemudian digulung selanjutnya dikocok dan diambil satu kelas untuk dijadikan sampel penelitian. Setelah dilakukan pengundian dari keseluruhan populasi, maka didapatkan kelas X2 sebagai kelas ekperimen.

\section{Teknik Analisis Data}

Teknik analisis data yang dilakukan dalam penelitian ini terhadap hasil belajar siswa kelas eksperimen, Penulis menggunakan cara statistik yaitu rata-rata, simpangan baku, Uji Normalitas, dan Uji Hipotesis t-tes. Namun, sebelum dilakukan penelitian dikelas penelitian, terlebih dahulu dilakukan uji coba instrument yaitu validitas, reliabilitas, daya pembeda, dan tingkat kesukaran. Berdasarkan perhitungan uji coba instrument diketahui bahwa soal yang dapat digunakan sebanyak 6 soal.

\section{HASIL DAN PEMBAHASAN Deskripsi dan Analisis Tes Awal Siswa (pre-test)}

Rata dan Simpangan Baku Pada Pre-test

Berdasarkan hasil perhitungan data pre-test, rekapitulasi analisis data hasil pre-test dapat dilihat pada tabel 3

Tabel 3 Rekapitulasi Hasil Tes Awal

\begin{tabular}{llcc}
\hline No & Uraian & $\begin{array}{l}\text { Kelas } \\
\text { Eksperimen }\end{array}$ & Kelas Kontrol \\
\hline $\mathbf{1}$ & Rentang Nilai & 45 & 42 \\
$\mathbf{2}$ & Nilai Rata-rata & 32.85 & 30.75 \\
$\mathbf{3}$ & Simpangan & 11.19 & 9.89 \\
& Baku & & \\
$\mathbf{4}$ & Nilai Terkecil & 20 & 15 \\
$\mathbf{5}$ & Nilai Terbesar & 65 & 57 \\
\hline
\end{tabular}

Berdasarkan tabel 3 dapat dilihat bahwa skor rata-rata kelas eksperimen 32.85 dengan simpangan baku 11.19 sedangkan kelas kontrol skor rata-rata 30.75 dengan simpangan baku 9.89. Dari data menunjukkan selisih skor rata-rata tes awal kelas eksperimen dan kelas kontrol 2.1 sedangkan selisih simpangan baku kedua kelas tersebut adalah sebesar 1.3. Data tersebut menunjukkan kemampuan awal kelas ekperimen secara deskriptif dapat dikatakan bahwa kemampuan awal siswa sebelum pengaruh model pembelajaran Demonstrasi termasuk kategori belum tuntas.

\section{Uji Normalitas Pada Pre-test}

Uji normalitas bertujuan untuk mengetahui apakah data hasil tes siswa berdistribusi normal atau tidak. Untuk mengetahui kenormalan data, digunakan uji normalitas data dengan uji kecocokan $\chi^{2}$ (Chi-Kuadrat). berdasarkan ketentuan perhitungan statistik mengenai uji normalitas data dengan taraf kepercayaan $\alpha=95 \%$, jika $\chi^{2}$ hitung $<\chi^{2}$ tabel maka data berdistribusi normal, akan tetapi sebaliknya jika $\chi^{2}$ hitung $>\chi^{2}$ tabel maka data tidak berdistribusi normal. Hasil perhitungan uji normalitas dapat dilihat pada tabel 4 
Tabel 4 Hasil Uji Normalitas Skor Pre-Test

\begin{tabular}{ccccc}
\hline Kelas & $\chi_{\text {hitung }}^{2}$ & Dk & $\chi_{\text {tabel }}^{2}$ & Kesimpulan \\
\hline Eks & 10,6535 & 5 & 11,070 & Normal \\
Kon & 10,4525 & 5 & 11,070 & Normal \\
\hline
\end{tabular}

Kelas eksperimen didapat nilai $\chi_{\text {hitung }}^{2}=10,6535$ dan pada kelas kontrol di dapat nilai $\chi_{\text {hitung }}^{2}=10,4525$. Berdasarkan ketentuan perhitungan statistik mengenai uji normalitas data dengan taraf kepercayaan $\alpha=0,05$, jika $\chi_{\text {hitung }}^{2}<\chi_{\text {tabel }}^{2}$, maka data nilai pre-test (tes awal) kedua kelas eksperimen dan kontrol berdistribusi normal.

\section{Deskripsi dan Analisis Data Tes Akhir Siswa (Post-Test)}

Kemampuan akhir siswa yang dimaksud dalam penelitian ini adalah hasil belajar siswa setelah mengikuti proses pembelajaran dengan menggunakan pembelajaran kooperatif tipe Think Pair Share, suatu hasil belajar berada pada kategori tuntas ketika nilai siswa telah mencapai KKM. Post-test dalam penelitian ini dilakukan pada tanggal 17 april 2017 yang diikuti oleh 30 siswa di kelas yang telah ditentukan sebagai sampel.

\section{Rata dan Simpangan Baku Pada Post-test}

Berdasarkan hasil perhitungan data post-test, rekapitulasi hasil tes akhir siswa dapat dilihat pada tabel 5

Tabel 5 Rekapitulasi Hasil Post-Test

\begin{tabular}{llcc}
\hline No & Uraian & \multicolumn{1}{l}{$\begin{array}{l}\text { Kelas } \\
\text { Eksper } \\
\text { imen }\end{array}$} & $\begin{array}{l}\text { Kelas } \\
\text { Kontrol }\end{array}$ \\
\hline $\mathbf{1}$ & Rentang Nilai & 45 & 60 \\
$\mathbf{2}$ & Nilai Rata-rata & 80.45 & 59.48 \\
$\mathbf{3}$ & Simpangan & 12.25 & 11.28 \\
& Baku & & \\
$\mathbf{4}$ & Nilai Terkecil & 50 & 20 \\
$\mathbf{5}$ & Nilai Terbesar & 95 & 80 \\
\hline
\end{tabular}

Berdasarkan tabel 5 dapat dilihat bahwa skor rata-rata kelas eksperimen 80.45 dengan simpangan baku 12.25 sedangkan kelas kontrol skor rata-rata 59.48 dengan simpangan baku 11.28. Jadi dapat dikatakan bahwa hasil post-test siswa setelah mengikuti pembelajaran dengan model pembelajaran Demonstrasi meningkat dan mencapai KKM.

\section{Uji Normalitas}

Uji normalitas bertujuan untuk mengetahui apakah data hasil tes siswa berdistribusi normal atau tidak. Untuk mengetahui kenormalan data, digunakan uji normalitas data dengan uji kecocokan $\chi^{2}$ (Chi-Kuadrat). berdasarkan ketentuan perhitungan statistik mengenai uji normalitas data dengan taraf kepercayaan $\alpha=95 \%$, jika $\chi^{2}$ hitung $<\chi^{2}$ tabel maka data berdistribusi normal, akan tetapi sebaliknya jika $\chi^{2}$ hitung $>\chi^{2}$ tabel maka data tidak berdistribusi normal. Hasil perhitungan uji normalitas dapat dilihat pada tabel 6

Tabel 6 Hasil Uji Normalitas Skor Pos-Test

\begin{tabular}{ccccc}
\hline Kelas & $\chi_{\text {hitung }}^{2}$ & Dk & $\chi_{\text {tabel }}^{2}$ & Kesimpulan \\
\hline Eks & 10,6535 & 5 & 11,070 & Normal \\
& & & & \\
Kon & 10,4525 & 5 & 11,070 & Normal \\
\hline
\end{tabular}

Kelas eksperimen didapat nilai $\chi_{\text {hitung }}^{2}=10,6535$ dan pada kelas kontrol di dapat nilai $\chi_{\text {hitung }}^{2}=10,4525$. Berdasarkan ketentuan perhitungan statistik mengenai uji normalitas data dengan taraf kepercayaan $\alpha=0,05$, jika $\chi_{\text {hitung }}^{2}<\chi_{\text {tabel }}^{2}$, maka data nilai pre-test (tes awal) kedua kelas eksperimen dan kontrol berdistribusi normal

\section{Pengujian Hipotesis}

Hipotesis penelitian yang diuji adalah hasil belajar setelah menerapkan metodepembelajaran Demonstrasi pada pembelajaran fisika di kelas $\mathrm{X}$ Ma $\mathrm{Al}$ Muhajirin Tugumulyo tahun Ajaran 2016/2017 secara signifikan tuntas. Rumusan hipotesis statistik yang diuji dalam penelitian ini adalah:

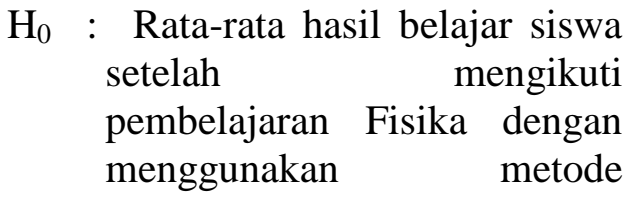




\section{pembelajaran Demonstrasi kurang dari $\left(\mu_{0}<74\right)$ \\ $\mathrm{H}_{\mathrm{a}}$ : Rata-rata hasil belajar siswa setelah mengikuti pembelajaran Fisika dengan menggunakan metode pembelajaran Demonstrasi lebih dari atau sama dengan $74\left(\mu_{0} \geq 74\right)$}

Kriteria pengujiannya adalah jika thitung < tabel maka $\mathrm{H}_{0}$ diterima dan $\mathrm{Ha}_{\mathrm{a}}$ ditolak, dan jika thitung > tabel maka $\mathrm{H}_{0}$ ditolak dan $\mathrm{Ha}_{\mathrm{a}}$ diterima pada taraf signifikansi yaitu $\alpha=95 \%$ dan $\mathrm{dk}=\mathrm{n}-1=$ $29-1=28$. Hasil uji hipotesis data posttest dapat dilihat pada tabel 7

Tabel 7 Hasil Uji Hipotesis Skor Post-test

\begin{tabular}{cccc}
\hline & $\mathbf{t}_{\text {hitung }}$ & $\mathbf{t}_{\text {tabel }}$ & Kesimpulan \\
\hline Tes Akhir & 6,87 & 2,02 & $\mathrm{H}_{\mathrm{o}}$ ditolak \\
\hline
\end{tabular}

Berdasarkan hasil perhitungan uji-t tentang kemampuan akhir menunjukkan bahwa $t_{\text {hitung }}>t_{\text {tabel }}$ yaitu $6,87>2,02$ yang menunjukkan bahwa nilai rata-rata kelas eksperimen lebih besar dari nilai rata-rata kelas kontrol. Sehingga hipotesis $\mathrm{H}_{\mathrm{o}}$ ditolak.

Permasalahan yang dibahas dalam penelitian ini yaitu apakah ada Pengaruh Metode Pembelajaran Demonstrasi terhadap Hasil Belajar Fisika siswa kelas $X$ MA Al-Muhajirin tugumulyo tahun pelajaran 2016/2017?. Penelitian ini dilakukan pada dua kelas sebagai sampel yaitu kelas $\mathrm{X}_{1}$ (eksperimen) dan $\mathrm{X}_{2}$ (kontrol). Peneliti menggunakan kelas XI $\mathrm{IPA}_{1}$, untuk pengujian instrumen tes pada tanggal 24 april 2017.

Kemudian kedua kelas diberi perlakuan yang berbeda yaitu kelas eksperimen diberi perlakuan dengan model Demonstrasi, dimana Metode pembelajaran Demonstrasi adalah salah satu metode pembelajaran kooperatif yang menekankan pada partisipasi dan aktifitas siswa untuk mencari jawaban dengan usaha sendiri berdasarkan fakta atau data yang benar. Sedangkan kelas kontrol diberi perlakuan dengan pembelajaran konvensional berupa ceramah dan tanya jawab.

Pada kelas eksperimen, diterapkan dengan model pembelajaran Demonstrasi, dalam penelitian ini tersebut siswa dibagi menjadi 6 kelompok yang terdiri dari 5 sampai 6 orang, kemudian setiap siswa dalam kelompok berdiskusi menjawab pertanyaan yang telah diberikan, kemudian hasil tersebut dipresentasikan. Pada saat presentasi inilah siswa yang tidak bisa akan bertanya sehingga yang kurang pandai mendapat bantuan dari teman yang lainnya. Melalui teman sendiri, siswa akan merasa nyaman tidak ada rasa malu sehingga diharapkan siswa yang kurang pandai tidak segan-segan untuk menanyakan kesulitan yang dihadapinya.

Pada pertemuan kedua pelaksanaan pembelajaran, tidak jauh berbeda dengan kondisi pada pertemuan pertama pada kelas eksperimen tetap menggunakan Metode pembelajaran Demontrasi dan pada kelas kontrol diterapkan pembelajaran konvensional berupa ceramah dan tanya jawab. Disini mereka pun sudah lebih memahami proses pelaksanaan pembelajaran tersebut, sehingga menjadi lebih mudah untuk mengarahkannya.

Dari hasil analisis pre-test (tes awal) skor rata-rata kelas eksperimen dan kelas kontrol terdapat perbedaan yang jauh, hal ini berarti kedua kelas memiliki kemampuan awal yang berbeda. Selanjutnya, dilanjutkan dengan menerapkan model pembelajaran Demonstrasi pada kelas eksperimen dan pembelajaran konvensional berupa ceramah dan tanya jawab pada kelas kontrol, kemudian diberikan post-test (tes akhir) untuk mengetahui hasil belajar siswa pada kedua kelas tersebut.

Berdasarkan hasil analisa data posttest (tes akhir) yang telah diberikan kepada siswa kelas eksperimen dan kelas kontrol terlihat bahwa kelas eksperimen yang diberikan pembelajaran fisika dengan menggunakan Metode pembelajaran Demonstrasi lebih baik dari pada hasil 
belajar siswa kelas kontrol dengan pembelajaran konvensional berupa ceramah dan tanya jawab. Hal ini terlihat dari rata-rata post-test (tes akhir) hasil belajar fisika siswa kelas eskperimen memperoleh nilai sebesar 80,45 dan simpangan baku 12,25. Sementara kelas kontrol setelah diberi perlakuan dengan pembelajaran konvensional berupa ceramah dan tanya jawab diperoleh skor rata-rata post-test (tes akhir) sebesar 59,48 dan simpangan baku 11,28.

Dengan demikian skor rata-rata kelas eksperimen lebih besar dari pada skor rata-rata kelas kontrol. Ini berarti bahwa hasil belajar kelas eksperimen yang menerapkan Metode pembelajaran Demonstrasi dapat meningkat lebih besar dari pada hasil belajar kelas kontrol dengan menerapkan pembelajaran konvensional berupa ceramah dan tanya jawab.

Peran guru dalam pembelajaran menggunakan Metode pembelajaran Demonstrasi ini adalah sebagai fasilitator bagi siswa dalam menemukan pengetahuan yang harus dimiliki siswa. Guru membimbing, mengarahkan dan memotivasi siswa dalam setiap kelompok serta merangsang keaktifan siswa untuk belajar mandiri menemukan pengetahuan yang baru. Hal ini membantu siswa memahami dan mengingat pengetahuan yang didapatnya dan bertahan lebih lama dalam ingatannya.

Berdasarkan hasil penelitian yang dilakukan pada kelas X Ma Al Muhajirin Tugumulyo, hasil belajar menggunakan pembelajaran konvensional berupa ceramah dan tanya jawab lebih kecil dibandingkan dengan hasil belajar menggunakan Metode pembelajaran Demonstrasi.

Pembelajaran ceramah ternyata memiliki kelemahan dimana kegiatan belajar lebih berpusat pada guru, siswa hanya karena mereka terbiasa hanya menerima materi yang dijelaskan guru, walaupun mereka sama sekali tidak termotivasi dan tidak tertantang untuk belajar, sehingga tidak tertarik dengan apa yang dijelaskan oleh guru. Keadaan demikian membuat situasi belajar menjadi tidak konduksif dan siswa menjadi pasif. Selanjutnya hasil penelitian yang telah dilakukan peneliti berjudul “ Pengaruh Metode pembelajaran Demonstrasi terhadap hasil belajar fisika siswa kelas $\mathrm{X}$ Ma Al-Muhajirin Tugumulyo tahun pelajaran 2016/2017" dalam hal ini memberikan informasi bahwa hasil analisis data tes awal melalui uji-t dengan taraf kepercayaan $\alpha=0,05$ didapat hasil $t_{\text {hitung }}=1,01$ dan $t_{\text {tabel }}=2,01$ sehingga $t_{\text {hitung }}$ $<t_{\text {tabel. }}$ Kemudian hasil analisis data tes akhir melalui uj-t dengan taraf kepercayaan $\alpha=0,05$ didapat hasil $t_{\text {hitung }}$ $=6,87$ dan $t_{\text {tabel }}=2,02$ sehingga $t_{\text {hitung }}>$ $\mathrm{t}_{\text {tabel. }}$.

Dengan demikian ada pengaruh yang signifikan Metode pembelajaran Demonstrasi terhadap Hasil Belajar Fisika siswa kelas $\mathrm{X}$ Ma Al-Muhajirin Tugumulyo Pelajaran 2016/2017. Sesuai dengan apa yang diungkapkan oleh Suyono (2011) hasil belajar dipengaruhi oleh pengalaman pelajar sebagai hasil interaksi dengan dunia fisik dan lingkungannya.

\section{SIMPULAN}

Berdasarkan hasil penelitian dan pembahasan, didapat hasil uji normalitas pretest (test awal) untuk kelas eksperimen sebesar 10,6535 dan kelas kontrol 10,4525, sedangkan pada kelas posttest didapat kelas eksperimen 10.9835 dan kelas kontrol 9,8328 untuk perhitungan tarap keprcayaan $\alpha=0,05$ maka $\chi 2_{\text {hitung }<\chi} 2_{\text {tabel }}$ berdistribusi normal, untuk kemampuan akhir siswa dapat dibuktikan bahwa thitung $(6,87)>$ ttabel $(2,02)$ yang berarti $\mathrm{Ha}$ diterima. Disimpulkan bahwa ada pengaruh yang signifikan Metode pembelajaran Demonstrasi terhadap hasil belajar fisika siswa kelas $\mathrm{X}$ Ma Al-Muhajirin 2016/2017. 


\section{DAFTAR PUSTAKA}

Djamarah, Bahri , Syaiful dan Zain, Aswan. (1997). Strategi belajar mengajar. Jakarta : Renika Cipta.

Majid, Abdul. (2013). Srategi Pembelajaran. Bandung: Remaja rosdakarya.

Sudjana, Nana. (2004). Dasar-dasar proses pembelajaran. Bandung: Sinar Baru Algensindo.

Suyono. (2011). Belajar dan pembelajaran. Bandung: Remaja Rosdakarya. 